\title{
Belgeo
}

Revue belge de géographie

1-2 | 2012

Inaugural issue

\section{Scale and the workplace as level of analysis in transport geography}

Echelle et lieu de travail en tant que niveau d'analyse en géographie des transports

\section{Thomas Vanoutrive}

\section{CpenEdition}

\section{Journals}

Electronic version

URL: http://journals.openedition.org/belgeo/6229

DOI: $10.4000 /$ belgeo.6229

ISSN: 2294-9135

\section{Publisher:}

National Committee of Geography of Belgium, Société Royale Belge de Géographie

\section{Electronic reference}

Thomas Vanoutrive, "Scale and the workplace as level of analysis in transport geography », Belgeo

[Online], 1-2 | 2012, Online since 15 December 2012, connection on 19 April 2019. URL : http:// journals.openedition.org/belgeo/6229; DOI : 10.4000/belgeo.6229

This text was automatically generated on 19 April 2019

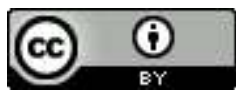

Belgeo est mis à disposition selon les termes de la licence Creative Commons Attribution 4.0 International. 


\title{
Scale and the workplace as level of analysis in transport geography
}

\author{
Echelle et lieu de travail en tant que niveau d'analyse en géographie des
}

transports

Thomas Vanoutrive

\section{Introduction}

1 According to Frändberg and Vilhelmson (2010), sustainable mobility is a critical issue for geography. They put forward three key questions to set a research agenda for transport geography. First, geographers can shed light on the link between the ever-increasing levels of (physical) mobility and social and spatial developments. A second research topic is the decoupling between economic growth and mobility demand. Finally, research has a role to play in policy and planning; this includes evaluating and formulating potential interventions that reduce physical mobility. These interventions are carried out "at various spatial scales and in various contexts" (p.113) like the city, neighbourhood, workplace, and home levels. The inclusion of a multitude of levels is a consequence of a focus on socio-spatial structures which contrasts with the dominant approach that focuses on individual and household behaviour. Given the increasing attention on workplaces in transport policy-making, we here discuss the role of the workplace level in commuting and the relation with other levels. The present paper explores the topic using some explorative measures and briefly discusses some methodological issues. The discussion contains some elements which are useful to develop a research agenda.

2 The role of workplaces in commuting has changed over time. At a general level, the shift from Fordism to Post-Fordism offers a good framework to highlight some relevant evolutions. In a somewhat simplified version, spending most of one's career with one employer was considered as the norm in the Fordist period while today this is interpreted as a lack of ambition. Regularly changing your job is viewed as a successful and logical career path. One of the consequences is that many employees will opt for long-distance 
commuting instead of relocating since assignments are considered temporary (Green, 2004). Furthermore, increased levels of female labour market participation and the related increase in dual-career households, together with the growing importance of the work-life balance, decreases the willingness "to relocate at the behest of an employer" (ibid., p. 632). Increased welfare, growing complexity and flexibility and the less central position of work in travel behaviour makes the private car even more popular than before due to its high degree of flexibility.

3 Policy-making practices have changed too. Transport policy was influenced by the restructuring of national states which encompasses the rise of supra-national institutions which develop own transport strategies (e.g. European Commission, 2011), the decreased willingness to intervene in supposed market-led societal processes, regionalist tendencies, and devolution of competences to sub-national spaces of governance (MacKinnon and Shaw, 2010). From a somewhat different perspective, Lyons and Urry (2005) suggest that we are in the third age of transport studies and planning, the age of transport demand management. In the first age the focus was on highway design, construction and maintenance. Then the focus gradually shifted towards the management of this infrastructure (i.e. network and traffic management). While considerable means are still spent on infrastructure and traffic management, terms like Transport Demand Management and Mobility Management are increasingly used in policy documents. Lyons and Urry $(2005$, p. 274$)$ define this demand management perspective as "understanding our lifestyle needs and determining and influencing how the transport system is best used to support those needs". This approach puts more emphasis on soft measures that change travel behaviour like financial incentives and advertisements instead of hard measures like the building of new infrastructure (Cairns et al., 2008). This is where employers and workplaces enter the scene (Cairns et al., 2010). Employers have a privileged contractual and financial relationship with commuters and, as a result, have the ability to influence (travel) behaviour using a multitude of soft transport measures. For this reason, governments attempt to involve employers in their transport policies as a kind of intermediate institutions between themselves and commuters (DeHart-Davis and Guensler, 2005).

4 As mentioned earlier, Frändberg and Vilhelmson (2010) argue that besides the individual or household level other relevant scales should be taken into account like the city, neighbourhood, and workplace. This suggests that the workplace level might be considered as a scale. However, in human geography there are few concepts as heavily debated as scale (Brenner, 2001 ; Marston and Smith, 2001; Marston et al., 2005 ; Leitner and Miller, 2007). We summarise the scale debate in an Annex and argue that workplaces have ontological status, i.e. workplaces are real material things which are relevant for transport geography. However, we will not employ the scale concept as it is understood in the work of "scalist" authors (Jonas, 2006). That is why we largely ignore this literature in the main body of the text. In contrast, this essay focuses on some quantitative and methodological concerns.

5 In what follows we discuss the role of the workplace in commuting research by means of an empirical exercise which tries to reveal whether this level is an appropriate unit to analyse modal choice. This is done using variance partitioning (Section 2). To illustrate how a different angle can influence our view on the topic, we provide a networked view on the workplace as well (Section 3). Section 4 discusses the workplace as level from a methodological perspective. Finally, Section 5 concludes. 


\section{Vertical approach}

In the statistical literature, several research strands focus on hierarchical relations in data, like multilevel studies which take into account the nested nature of observational units. The rationale of multilevel techniques is that observations within the same group have similar values, which is a violation of the independence assumption in standard regression analysis. The most well-known examples of multilevel studies are found in educational science, where pupils are nested in classes, which are, on their turn, nested in schools (Goldstein, 1995 ; Hox, 2002). Nowadays, multilevel modelling is applied in a wide range of research disciplines like epidemiology (Merlo et al., 2009), political science (Johnston et al., 2007) and transport research (Schwanen et al., 2004; Vanoutrive et al., 2009 ; 2012a).

7 Most multilevel scholars refer to the ecological and atomistic fallacies to motivate their choice for this technique (Duncan et al., 1998 ; Langford et al., 1998; Subramanian et al., 2001 ; Mohan et al., 2005 ; French and Jones, 2006). The risk of ecological fallacy implies that researchers must be cautious when transferring results based on aggregated data to individuals that belong to these aggregates (Robinson, 1950). For example, suppose that the share of rail use is higher at sites with higher shares of female employees. On the basis of these facts, one may not conclude that female employees are more frequent rail users, since it is still possible that all rail users are male. A hidden variable, like a higher share of female employees in central government offices, can explain this finding since government offices are often located near railway stations. Note that assumptions can be made about individuals in aggregated data on the basis of previous empirical research or theoretical considerations.

8 A particular form of ecological fallacy is the Modifiable Areal Unit Problem (MAUP, Openshaw and Taylor, 1981; Johnston et al., 2000, p. 518-519). MAUP is the "phenomenon whereby different results are obtained in analysis of the same data grouped into different sets of areal units" (Manley et al., 2006, p. 144). This problem can be subdivided in a zoning and a scale effect. Firstly, the zonation issue concerns the effect of the arbitrary nature of the boundary division. Indeed, the aggregation of the same data in different configurations of spatial units can lead to dramatically different results. Secondly, the scale issue covers the change of results when the level of analysis changes. As a result, the aggregation of commuters in different sets of geographical areas might have a significant impact on the correlations found between the variables of interest.

Less known than ecological fallacy is the concept of atomistic fallacy. Indeed, researchers must also be cautious when they transfer relationships at the individual level to aggregates of individuals. For example, a survey can reveal that men are more frequent rail users than women; however, one can measure lower levels of rail use at worksites with a higher share of male employees since these sites are located in areas with lower levels of rail accessibility. Multilevel approaches model different levels simultaneously; both the individual and the aggregated level can thus be part of the same model. This characteristic helps to avoid committing the ecological as well as the atomistic fallacy. In contrast, standard regression models often aggregate the data at the highest level (e.g. municipality), which results in information loss and a higher risk of ecological fallacy (Langford et al., 1998). Other models only use data at the individual level or attribute the same value to all observations in the same group, which results in a higher risk of 
atomistic fallacy. Indeed, the reductionist assumption that aggregated behaviour measured at a higher level equals the sum of the behaviour of all individuals is often not valid since one cannot grasp the entire complexity of all relevant characteristics of, and relations between, constituent elements. As a consequence, the whole might be more than the sum of its parts.

In essence, multilevel regression models estimate a regression line for each predefined group of observations, but all these lines are part of one main model. Examples in transport research can be found in e.g. Bhat (2000), Schwanen et al. (2004), Kwan and Weber (2008), and Vanoutrive et al. $(2009 ; 2012 a ; 2012 b)$. With multilevel techniques, one can determine the intra class correlation (ICC), a measure that estimates to which extent the value of an observation is determined by its peer (class). In a multilevel modelling setting, measuring the ICC is regularly used to check which amount of the total variance can be attributed to the different levels, and is therefore called Variance Partition Coefficient (VPC) or Intra-Area Correlation (IAC) in case of spatial data. This variance partitioning is a valuable tool to estimate the relative importance of different levels and to explore at which level the action lies (Subramanian et al., 2001).

\section{Vertical approach : method and data}

11 In this section we employ the simplest hierarchical tool, the VPC, to find out whether the workplace level matters or not in commuting behaviour. Our focus is on mode choice but the measure can also be applied on other travel characteristics (e.g. Schwanen and Dijst, 2002). In the case of modal choice, the dependent variable is not continuous; as a result, standard ICC measures cannot be applied. If mode choice is measured at the individual level, the dependent variable is a dummy which takes a value of 1 if an employee commutes by the respective mode, and 0 otherwise. We assume that a continuous latent variable (e.g. car addiction, cycling utility) underlies the modal choice of an employee, which is measured by some binary variables (car user or not ; cyclist or not,...). The level 1 variance equals $\pi^{2} / 3$ since a logistic regression is used. Using this assumption, the variance can be attributed to the different levels in the data. For an extensive discussion and more complex issues we refer the reader to Browne et al. (2005).

In order to make the analysis more robust, we employ three different samples. The first sample contains the 1087 workplaces of the Manufacturing sector in Belgium. In total, 312853 employees commute to these workplaces, which are located in 293 different municipalities. We selected these observations out of the Belgian questionnaire home to work travel (HTWT) 2005. In this questionnaire, large Belgian companies $(\geq 100$ employees) report per workplace ( $\geq 30$ employees) among others the number of employees that commute with a given mode. For more information on this questionnaire we refer the reader to Vanoutrive et al. (2010). Although this survey is carried out at the workplace level, we can compute the dependent variable at the employee level since the number of employees and the share of each mode is available for each workplace.

The second dataset is a subsample of the database HTWT 2005 too. In order to explore the difference between organisational and spatial characteristics of workplaces, we selected companies with at least 20 workplaces in Belgium. Workplaces of governments were excluded to avoid a public-private dichotomy (note that semi-public companies were included). We constructed two hierarchies which nest employees in workplaces. In a first hierarchy, workplaces were grouped in companies since we assume that organisational 
practices are more homogeneous among workplaces of the same company. A second exercise creates a spatial hierarchy and nests these workplaces in municipalities. In the latter case, mainly locational characteristics like accessibility make that observations within the same group (municipality) are more similar. Although both hierarchies can be included in one model (Browne et al., 2007), they were modelled separately to keep the models as parsimonious as possible.

The third sample contains the employees of 91 workplaces in the Brussels Capital region for which data at the individual level is present in the database of the environmental department of this region (Institut Bruxellois pour la Gestion de l'Environnement, Brussels Instituut voor Milieubeheer, IBGEBIM). This database is constructed with data collected in the framework of the mandatory travel plans for large companies located in Brussels (since 2004-2005). Note that the selected workplaces are also present in the database HTWT 2005 which we used in the previous samples. In contrast with these samples, the municipality level is not added since these workplaces are all located in the Brussels Capital region. Furthermore, the soft modes walking and cycling are grouped in one category, motor drivers are added to the car category, and employer transport to the MTB group. The majority of workplaces in sample 3 does not belong to manufacturing (sample 1), given the prevalence of office-type workplaces in Brussels. Finally, note that Brussels is the largest city in Belgium. As a consequence, this agglomeration is the core of the main infrastructure networks, and the workplaces located there suffer more from congestion than those elsewhere in the country (Verhetsel et al., 2010).

\section{Vertical approach : results}

Table 1 shows the results of five multilevel binary logistic regressions which make use of the first sample which contains the employees of the manufacturing sector in Belgium. A separate regression is made for each mode, which allows to compute the Variance Partition Coefficient (VPC). This measure attributes the variance in the data to the different levels of a pre-specified hierarchy (by definition, the sum is $100 \%$ ).

Table 1. Variance partitioning of five commuting modes at workplaces of the manufacturing sector in Belgium.

\begin{tabular}{|c|c|c|c|c|c|c|}
\hline & Car & Carpool & Rail & MTB & Bicycle \\
\hline \multirow{2}{*}{\multicolumn{2}{|c|}{$\begin{array}{l}\text { constant (s.e.) } \\
\text { municipality (s.e.) }\end{array}$}} & $1.30(0.04)$ & $-2.58(0.06)$ & $-4.34(0.17)$ & $-4.42(0.14)$ & $-2.51(0.06)$ \\
\hline & & $0.13(0.03)$ & $0.06(0.06)$ & $4.42(0.70)$ & $2.18(0.44)$ & $0.70(0.09)$ \\
\hline \multicolumn{2}{|c|}{ workplace (s.e.) } & $0.76(0.04)$ & $2.77(0.13)$ & $9.25(0.48)$ & $8.18(0.43)$ & $0.67(0.04)$ \\
\hline \multicolumn{2}{|c|}{ employee $\left(=\pi^{2} / 3\right)$} & 3.29 & 3.29 & 3.29 & 3.29 & 3.29 \\
\hline \multirow[t]{3}{*}{ VPC } & municipality & $3.0 \%$ & $1.0 \%$ & $26.1 \%$ & $16.0 \%$ & $15.0 \%$ \\
\hline & workplace & $18.1 \%$ & $45.3 \%$ & $54.5 \%$ & $59.9 \%$ & $14.3 \%$ \\
\hline & employee & $78.9 \%$ & $53.8 \%$ & $19.4 \%$ & $24.1 \%$ & $70.7 \%$ \\
\hline \multicolumn{2}{|c|}{ modal share (\%) } & 74.2 & 9.4 & 1.4 & 1.3 & 7.6 \\
\hline
\end{tabular}

Notes : level 3 : municipality ( $n=293)$; level 2 : workplace $(n=1087)$; level 1 : individual employee $(n=312853)$; s.e. : standard error ; VPC : Variance Partition Coefficient ; MTB : Metro Tram and Bus.

Data source : database HTWT 2005. Software : MLwiN.

16 The results indicate that the workplace determines 14 to $60 \%$ of the modal choice of employees in manufacturing. The municipality where the workplace is located matters particularly for public transport and the bicycle. Compared to other modes, using the car 
for commuting seems primarily dependent on individual characteristics of employees, since only one fifth of the variance is attributed to the workplace and municipality levels together. Finally, the use of the bicycle seems less dependent on workplace-related factors.

In Table 2, the first set of variance components models is similar to those in Table 1, i.e. a spatial hierarchy is employed (employee/ workplace/ municipality). However, the sample is quite different as only companies with at least 20 workplaces are part of the analysis. This number of 20 guarantees that there are enough observations at the second level (workplace) to ensure that the models can distinguish this level from the third level (company). The activity sector varies from public transport companies and postal services over a telecom operator to large retail enterprises and a university.

The differences between modes in Table 2 are similar to those found in the manufacturing sector (Table 1). Workplace location does not matter for carpooling and also the choice for driving the car is not heavily dependent on the location of a workplace in a given municipality. For commuting by bike and public transport location matters more (Verhetsel and Vanelslander, 2010). The models with an organisational hierarchy reveal that the workplace and the company one is working for have a considerable influence on modal choice.

Table 2. Variance partitioning of five commuting modes at workplaces of companies with at least 20 workplaces in Belgium.

\begin{tabular}{|c|c|c|c|c|c|c|}
\hline \multicolumn{7}{|c|}{ Spatial hierarchy } \\
\hline \multicolumn{2}{|c|}{$\overline{c o n s t a n t ~(s . e .)}$} & $1.07(0.05)$ & $-3.77(0.07)$ & $-2.73(0.11)$ & $-3.31(0.12)$ & $-2.29(0.07)$ \\
\hline \multicolumn{2}{|c|}{ municipality (s.e.) } & $0.27(0.05)$ & $0.02(0.02)$ & $0.91(0.24)$ & $2.16(0.33)$ & $1.00(0.11)$ \\
\hline \multicolumn{2}{|c|}{ workplace (s.e.) } & $0.93(0.05)$ & $6.09(0.11)$ & $7.32(0.72)$ & $4.03(0.20)$ & $0.61(0.04)$ \\
\hline \multicolumn{2}{|c|}{ employee $\left(=\pi^{2} / 3\right)$} & 3.29 & 3.29 & 3.29 & 3.29 & 3.29 \\
\hline \multirow[t]{3}{*}{ VPC } & municipality & $6.0 \%$ & $0.2 \%$ & $7.9 \%$ & $22.8 \%$ & $20.5 \%$ \\
\hline & workplace & $20.6 \%$ & $64.8 \%$ & $63.5 \%$ & $42.5 \%$ & $12.4 \%$ \\
\hline & employee & $73.4 \%$ & $35.0 \%$ & $28.5 \%$ & $34.7 \%$ & $67.1 \%$ \\
\hline \multicolumn{2}{|c|}{ modal share (\%) } & 60.4 & 2.9 & 19.7 & 6.9 & 5.9 \\
\hline \multicolumn{7}{|c|}{ Organisational hierarchy } \\
\hline \multicolumn{3}{|c|}{ Car } & Carpool & Rail & MTB & Bicycle \\
\hline \multicolumn{2}{|c|}{ constant (s.e.) } & $0.73(0.18)$ & $-3.57(0.42)$ & $-2.29(0.29)$ & $-2.47(0.26)$ & $-2.46(0.19)$ \\
\hline \multicolumn{2}{|c|}{ company (s.e.) } & $0.59(0.19)$ & $3.32(1.09)$ & $1.55(0.51)$ & $1.33(0.43)$ & $0.69(0.23)$ \\
\hline \multicolumn{2}{|c|}{ workplace (s.e.) } & $0.61(0.03)$ & $4.31(0.20)$ & $2.20(0.10)$ & $0.95(0.05)$ & $1.41(0.07)$ \\
\hline \multicolumn{2}{|c|}{ employee $\left(=\pi^{2} / 3\right)$} & 3.29 & 3.29 & 3.29 & 3.29 & 3.29 \\
\hline \multirow[t]{3}{*}{ VPC } & company & $13.2 \%$ & $30.4 \%$ & $22.0 \%$ & $23.9 \%$ & $12.8 \%$ \\
\hline & workplace & $13.6 \%$ & $39.5 \%$ & $31.3 \%$ & $17.0 \%$ & $26.2 \%$ \\
\hline & employee & $73.3 \%$ & $30.1 \%$ & $46.7 \%$ & $59.1 \%$ & $61.0 \%$ \\
\hline \multicolumn{2}{|c|}{ modal share (\%) } & 60.4 & 2.9 & 19.7 & 6.9 & 5.9 \\
\hline
\end{tabular}

Notes : municipality $(n=320)$; company $(n=20)$; workplace $(n=1289)$; employee $(n=163691)$.

s.e. : standard error; VPC : Variance Partition Coefficient; MTB : Metro Tram and Bus.

Data source : database HTWT 2005. Software : MLwiN.

Note that when using the spatial hierarchy, estimates for rail and especially for carpooling are less reliable as we changed the standard convergence tolerance value in $10 \mathrm{e}^{-0.5}$ (rail) and $10 \mathrm{e}^{-0.001}$ (carpool) respectively, since we could not reach convergence with the default value of $10 \mathrm{e}^{-2}$. 
Table 3 shows the results of five binary logistic regressions which make use of the IBGEBIM data on workplaces in Brussels. Although this sample might be more homogeneous than the previous ones, still $25 \%$ to $40 \%$ of the variance can be attributed to the workplace level.

Table 3. Variance partitioning of five modes at 91 selected workplaces in the Brussels Capital Region.

\begin{tabular}{llllll} 
& Car & Carpool & Rail & MTB & Soft \\
\hline constant (s.e.) & $-0.32(0.11)$ & $-3.44(0.15)$ & $-0.68(0.13)$ & $-1.51(0.11)$ & $-3.51(0.14)$ \\
workplace $(\mathrm{s.e.})$ & $1.01(0.15)$ & $2.02(0.31)$ & $1.46(0.22)$ & $1.11(0.17)$ & $1.61(0.25)$ \\
employee $\left(=\pi^{2} / 3\right)$ & 3.29 & 3.29 & 3.29 & 3.29 & 3.29 \\
& & & & & \\
VPC workplace & $23.5 \%$ & $38.1 \%$ & $30.7 \%$ & $25.2 \%$ & $32.8 \%$ \\
$\quad$ employee & $76.5 \%$ & $61.9 \%$ & $69.3 \%$ & $74.8 \%$ & $67.2 \%$ \\
modal share (\%) & $42.4 \%$ & $2.7 \%$ & $34.7 \%$ & $17.1 \%$ & $3.1 \%$ \\
\hline
\end{tabular}

NOTES : LEVEL 2 : WORKPLACE ( $\mathrm{N}=91)$; LEVEL 1 : INDIVIDUAL EMPLOYEE $(\mathbf{N}=57110)$; S.E. : STANDARD ERROR ; VPC : VARIANCE PARTITION COEFFICIENT ; CAR : CAR + MOTO ; MTB : METRO TRAM AND BUS + EMPLOYER TRANSPORT ; SOFT : BICYCLE + WALK.

DATA SOURCE : IBGEBIM. SOFTWARE : MLWIN.

\section{Vertical approach: discussion}

21 The Variance Partition Coefficients (VPCs) indicate that the workplace and municipality explain a significant part of the modal choice of commuters. A too narrow focus on the individual in commuting research thus holds the risk of ignoring work- and locationrelated factors. We agree that computing VPCs is a purely data-driven method which does not reveal why the workplace and the company are relevant levels of analysis. For instance, individual commuters are not randomly distributed among workplaces; a caraddict will in the first place apply for jobs near highways, while a confirmed cyclist has a more limited and different range of job opportunities. The selection individuals make between different job opportunities, together with the search for a place of residence, are main determinants of commuting behaviour (van Ommeren et al., 1999 ; Levinson and Wu, 2005 ; Newman and Bernardin, 2010). However, self-selection, endogeneity and related issues (Subramanian, 2004 ; van Wee, 2009) do not lower the importance of the workplace in commuting. Indeed, these processes explain the role the workplace plays in commuting and thus confirm that this level may not be ignored.

The added value of hierarchical techniques like variance partitioning is clear. They reveal which part of the variance in the data can be attributed to a given level of analysis. As a result, VPC is a useful tool to check whether the chosen level of analysis is relevant. For example, somebody who employs the manufacturing sample (Table 1) to analyse the distribution of carpooling among Belgian municipalities might only explain a large amount of very little (Merlo et al., 2009) since only $1 \%$ of the variance in the data can be attributed to this level. For this reason, the VPC disserves the same status as standard correlation coefficients. It certainly has drawbacks and it does not explain much, but as an exploratory tool it is not inferior to correlation coefficients which are also sensitive to outliers and the like.

We estimated the VPC for different samples in order to replicate the experiment. Nevertheless, we acknowledge that more divergent samples can be found elsewhere. 
Furthermore, the VPC method is rigid since it employs a strict hierarchical structure, employees are nested in workplaces and workplaces are nested in municipalities. More complex nesting structures can be employed (Browne et al., 2007) but the lens through which the data is observed remains hierarchical and fixed. Clustering methods like automated zoning algorithms can be applied to maximise the internal homogeneity of geographical areas through the generation of an "optimal zoning" (Openshaw and Taylor, 1981 ; Martin et al., 2001 ; Haynes et al., 2007 ; Flowerdew et al., 2008). One of the most wellknown examples is the delimitation of Travel To Work Areas (TTWAs) on the basis of commuting flows (e.g. De Wasseige et al., 2000). A thoughtful construction of the levels of analysis makes the use of predetermined observational units less problematic. Note that the selection of the workplace as meaningful level of analysis is mainly based on theoretical considerations.

While we may distinguish the workplace and company levels as meaningful units, it is less evident to consider administrative areas like municipalities as meaningful aggregates of commuters. For some transport modes (cycling and public transport) the municipality level seems to be relevant, but we cannot exclude the presence of MAUP at this level. Indeed, both multilevel scholars (Groenewegen et al., 1999 ; Langford et al., 1999 ; Blakely and Woodward, 2000 ; Merlo et al., 2009), as well as others (Brunsdon et al., 1998; Fotheringham et al., 2000), warn for the use of predefined spatial hierarchies in multilevel modelling. Authors must be critical when choosing a given spatial subdivision of a territory to aggregate individuals. Among others Kwan and Weber (2008) made a critical comparison between a list of accessibility measures and different spatial configurations to measure the relation between accessibility and scale, and the impact of the modifiable unit problem (MAUP). They conclude that the area-level variance is in most cases negligible as the large majority of the variance was attributed to the individual level. Using this kind of areas thus holds the risk of explaining a large amount of very little. In our samples, 10 to $25 \%$ of the variance in public transport use was attributed to the municipality level. For cycling, values lie between 15 and $25 \%$, while the results for driving the car (around $5 \%$ ) and carpooling (1\%) were lower. Our results indicate that workplaces are more relevant units to aggregate commuters than the often arbitrary administrative areas. However, data availability often prevents researchers from including the workplace as level of analysis.

As an alternative to administrative subdivisions of a territory, functional zones can be used. Travel To Work Areas (TTWA) and Daily Urban Systems (DUS) are seen as meaningful entities since their spatial extent coincides with daily labour markets (Herod, 2011). However, in the analysis above, we searched for smaller entities to better isolate the impact of the workplace from the influence of the wider environment. Another empirical issue is the sample size. In our analysis, we used 312 853, 163 691, and 57110 employees respectively. Presumably, the fact that almost all coefficients are significant is a consequence of these large sample sizes. Subsampling or running separate models for different groups can be options to give a smaller dataset that is easier to manage (Browne et al., 2005).

Finally, individual commuters are not only nested in workplaces, but also in their areas of residence. Each individual thus belongs to at least two hierarchies, (1) the workplace hierarchy, and (2) the residential hierarchy (commuter-household-neighbourhood-...). As shown by Bhat (2000), cross-classified multilevel models can be applied to take both hierarchies into account. Indeed, commuters are (spatially) clustered both at the home 
and at the work end of the commute. Empirical results of among others Chen et al. (2008) indicate that factors at the work end of the commute influence travel behaviour more than those at the residential end ; however, characteristics of both origin and destination neighbourhoods matter (Manaugh et al., 2010).

\section{A network perspective}

One of the reasons to consider workplaces as meaningful entities is that they act as social environments with a particular (corporate) culture where the behaviour and opinions of colleagues might influence your travel behaviour (Bonham and Koth, 2010; Heinen et al., 2011 ; McDonald, 2007 ; Vanoutrive et al., 2012b). Interventions of mobility management programmes at the workplace level are partly motivated by the belief that by influencing corporate culture and by creating a "buzz" around sustainable mobility employees will change their travel behaviour. Therefore, we explore in this section what happens inside the workplace by means of a small-scale survey, and we will look at the data from a network perspective. This different perspective brings about a different understanding of what a workplace is. The aim of the network analysis is thus not to compare two techniques (multilevel versus network), but to explore a different conceptualisation of workplaces. As a result, this analysis is less exhaustive than the hierarchical exploration in the previous section.

Contemporary society and science is characterised by a focus on network-like structures and complex systems in general (Escobar, 2007). This includes a focus on flows and movement in contrast with approaches that primarily deal with fixed, localised and/or sedentarist things (Sheller and Urry, 2006). Mobility and transport enable and constrain contacts between people and as a result, mobility must be taken into account to understand the structure and functioning of social networks (Axhausen, 2007). The interactions between elements in networks are not restricted to transport flows. As the example in this section shows, links between the constitutive elements of a network can represent many different things like information flows, opinions and influence (Leenders, 2002).

29 Also in quantitative studies (social) network analysis has increased in popularity (Butts, 2008). Interestingly, reference is often made to methodologies developed in quantitative geography and regional economics (e.g. Butts (2008) and Leenders (2002) refer to Anselin (1988)) since these tools take into account that "everything is related to everything else, but near things are more related than distant things", i.e. Tobler's first law of geography (Tobler, 1970, p. 236). Social network analysis then replaces geographical distance by social distance or influence (Leenders, 2002). Indeed, from a methodological perspective, spatial autocorrelation and network autocorrelation have much in common (Leenders, 2002; Peeters and Thomas, 2009). The following part offers a more complex view on a workplace by mapping the human constituent elements of a workplace and their relationships using a network approach.

\section{Network approach : Method and data}

A survey on the travel behaviour of colleagues was carried at the own department in January 2012 (Department of Transport and Regional Economics, University of Antwerp). All 28 persons who are regularly present at the workplace were asked how their 
colleagues travel to work (response rate $=100 \%$ ). Furthermore, they indicated, on a scale of 1 to 7, how well they know the travel behaviour of the other person. These selfassessments will be used to illustrate a network approach to the relationship between workplaces and travel behaviour. We assume that the higher the score, the more influence a colleague exert on your travel behaviour or, in social network terms, the smaller the social distance between colleagues. To have a rough indication of the travel behaviour of relatives and friends, we asked the same questions about the persons with whom they spent New Year's Eve. Table 4 provides the modal split figures. Note that these figures represent the main commuting mode and that several respondents indicated that they regularly travel to work using a different mode.

Table 4. Modal shares of department members and their relatives and friends.

\begin{tabular}{llcc} 
Mode & \multicolumn{3}{c}{ Relatives and Friends } \\
& Department TPR & weighted & unweighted \\
\hline Soft & 42.9 & 14.2 & 16.2 \\
Public Transport & 32.1 & 18.9 & 16.2 \\
Car & 25.0 & 66.9 & 67.7 \\
\hline $\mathrm{n}=$ & 28 & \multicolumn{3}{c}{136}
\end{tabular}

31 As a first step, graphical representations are regularly used to explore the structure of the network. Figure 1 gives an impression of the structure of the department. The thicker the (origin of the) line, the higher the person values her/his knowledge on the travel behaviour of the other person. Note that this is a bidirected graph by which the link between A and B might have a different score than the link between B and A. Although this graph shows which persons might be more prone to contagion by colleagues, it makes clear that it is hard to imagine the complex relationships between persons, even within a group of less than 30 persons. Therefore, some statistical analysis might enable us to test some hypotheses on the knowledge we have about the travel behaviour of colleagues.

32 A first hypothesis is that colleagues who travel with the same mode are more aware of each other's travel behaviour than two persons who commute using a different mode. Note that we here will not discuss whether this link is causal or not, i.e. a commuter can change mode since a colleague promoted an alternative based on his or her own experience with that mode. Second, the organisational hierarchy might have an influence on our knowledge. Do we know better the travel behaviour of persons with higher positions than that of people lower in the organisational hierarchy? To test these hypotheses we ran a logistic regression model that checks whether the link from person A to person $B$ has a value higher than 4 (on a scale from 1 to 7 ). The observations are the 756 edges between persons $\left(28^{2}-28\right)$ and we control for person-related effects to avoid that the difference between persons who give on average high scores and those who have lower scores will influence the results. 
Figure 1. Three-dimensional representation of the department based on stated knowledge of each others' travel behaviour. Software : R (R Development Core Team, 2010), gplot3d (Butts, 2008).

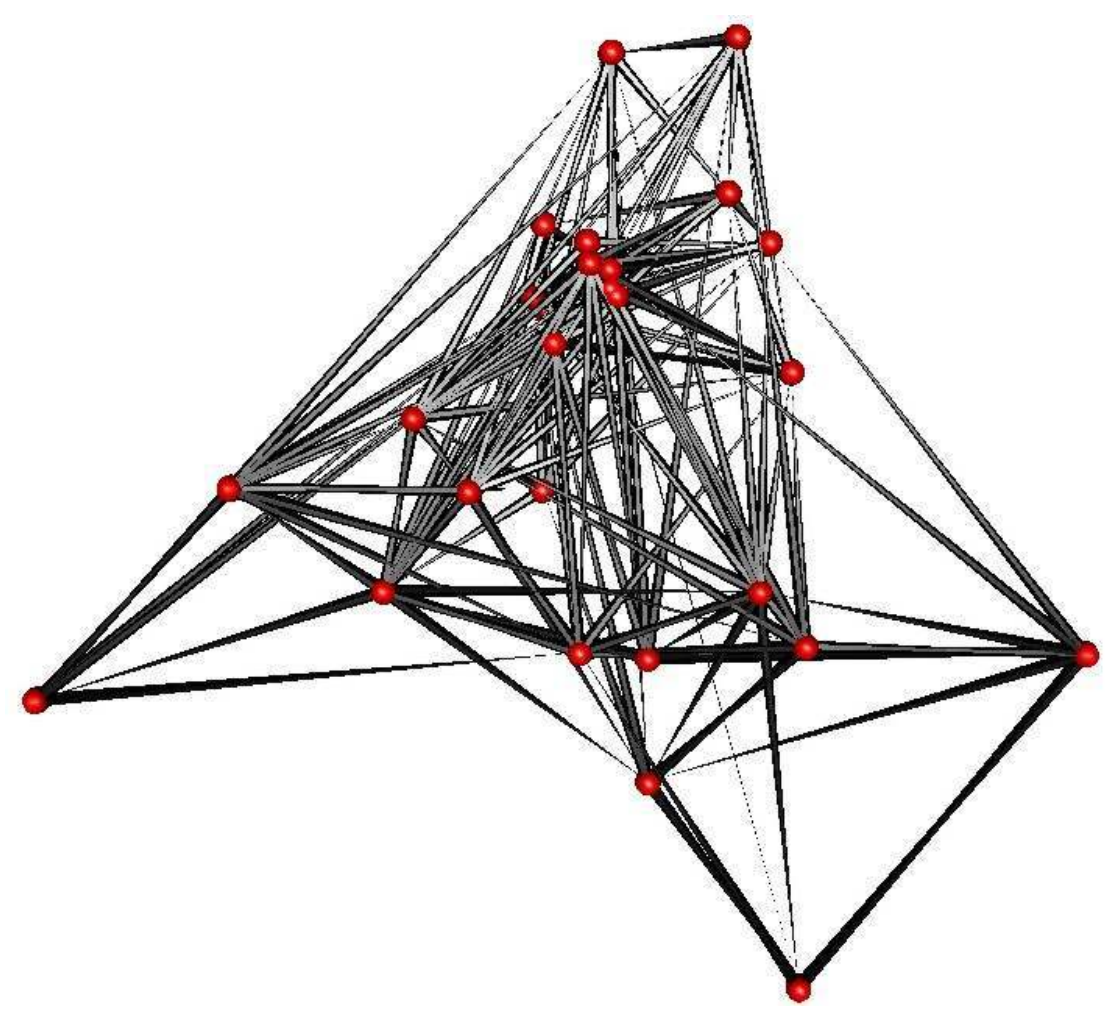

\section{Network approach : results}

Table 5 shows the results of the model. The random effects indicate that the person who was interviewed (sender) and the person of whom the travel behaviour was asked (receiver) did generally not significantly influence the dependent variable. The fixed effects show that members of the department generally stated that they know better the travel behaviour of professors and postdocs than that of $\mathrm{PhD}$ students and administrative staff. Furthermore, car drivers know each other's travel behaviour better than do transit users. We did not include relatives and friends in the model but department members stated that they know very well the travel behaviour of fellow partygoers (average score of 6.8 compared to 4.9 for colleagues). Note that the relatives themselves were not interviewed and that they form an extremely heterogeneous group in terms of location (Belgium, Cameroon, Egypt...) as well as other characteristics (income, education). 
Table 5. Results of the network regression model.

\begin{tabular}{llll}
$\begin{array}{l}\text { Random effects } \\
\text { Groups Name }\end{array}$ & \multicolumn{2}{l}{ Variance Std.Dev. } & $\mathrm{n}$ \\
\hline sender (Intercept) & 1.64 & 1.28 & 28 \\
receiver (Intercept) & 0.35 & 0.59 & 28
\end{tabular}

Fixed effects $(n=756)$ :

variable est

intercept

0.20

s.e.

$z$ value $\operatorname{Pr}(>|z|)$

both Transit

0.24

0.30

0.66

0.5069

both Soft

0.60

0.39

0.61

0.5454

both Car

1.86

0.32

1.87

0.0615 .

receiver prof

1.92

0.62

3.03

$0.0025^{* *}$

receiver postdoc

1.62

0.54

3.58

$0.0003^{* *}$

AIC BIC deviance (-2 loglikelihood)

$809.3 \quad 846.3 \quad 793.3$

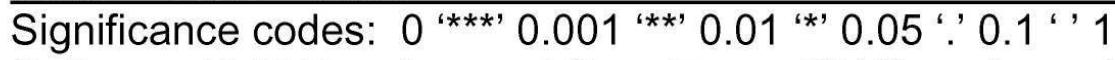

Software: R (R Development Core Team, 2010) package: Ime4

\section{Network approach : discussion}

In order to look from a different, less vertical, perspective to workplaces, we conducted a small case study and explored mode choice of the members of one workplace (department) using a network perspective. For reasons of simplicity, we ignored the fact that a workplace might consist of several departments. The analysis revealed that considering a workplace as a homogeneous aggregate of employees is a simplification of reality. Presumably, contagion effects are selective and peer pressure will affect some commuters more than others. Further analysis of this and other case studies might complement the more extensive research which makes use of a much larger sample. The switching back and forth between extensive and case study research (Eisenhardt, 1989 ; Richards, 2009) might enable us to develop a richer view on the role of the workplace in commuting.

We also, on purpose, made use of two different dimensions to approach the data. Instead of applying a vertical perspective to both the large dataset and the case study by e.g. nesting departments in faculties (which are part of universities) in line with multilevel theory in management science (Klein et al., 1999), we explored what happens inside a workplace by means of network analysis. This was partly inspired by multi-method approaches (e.g. Jones et al., 2010) and heuristics which refuse one-dimensionalism and approach a topic via a spiral movement along different potential entry points for analysis (Jessop et al., 2008).

Network-based approaches are appealing frameworks since they easily take into account agency (to avoid the structuralist fallacy), better reflect the tremendous complexity of the world, and impose less a priori's on observations since they start with the basic 
building blocks of structures and assemblages. However, what the constituent elements are is not clear. Even considering the individual (body) as basic unit of observation might be problematic (Herod, 2011), not to mention the inclusion of nun-human elements like baby seats, folding bikes and toys (as Schwanen (2007) did). Attributing too much value to micro-elements (e.g. trips or individual commuters) might lead to reductionism and the related atomistic fallacy, i.e. jumping to conclusions on aggregate behaviour solely on the basis of individual data and the interactions between them. This is observed by among others Wegener (2011, p.170) who got the impression that many microsimulation modellers believe that "the more micro the better". He questions whether the ongoing disaggregation and increasing complexity in microsimulation adds value to planning practice. Besides data availability and computer speed, the rationale for disaggregate models of individual behaviour is that a model should take into account different lifestyles, social networks of people, individual preferences and the interactions with other individuals and social groups. This kind of models thus rebuilds society with a copy of all individuals as building blocks and tries to reveal how land-use and travel patterns change. Wegener (2011, p. 162), referring to Einstein's "as simple as possible but no simpler", reminds us that the essence of good model making is simplifying the huge complexity of reality using a proper set of assumptions. To assess the interaction between land-use and transport, simpler models often provide insights equal to those based on the most complex algorithms. Similar observations are made in, for example, psychiatry where many scholars hold a biological reductionist perspective which implies that understanding psychiatric disorders just requires an understanding of neurobiological processes (Kendler, 2005). Both examples do not ignore individual agents or neurobiology respectively, but promote a multilevel perspective. A similar, more theoretical, call for a multilevel approach can be found in Whitmeyer (1994) who argues that a multilevel approach reflects the structure of scientific knowledge. At all levels of aggregation there exist "unit models" and an "aggregate of units at certain levels may be considered a unit at a higher (more macro) level if its parts tend to cohere in relation to its environment [...], if it seems to act as a single unit in its environment [...], or both" (p. 158). The advantages are that we can rely on models at another level when models fail, and that developments in models at one level might improve related models at different levels. Logically, conceptualisations at different levels may not contradict each other. The present paper started with the consideration that transport studies tend to focus on individual behaviour and that more levels of analysis should be taken into account (Frändberg and Vilhelmson, 2010). The focus of this article is on workplaces; however, we do not refuse work that focuses on individual or household behaviour (e.g. Gärling et al., 2002) but argue that putting individual travel behaviour into context using a multilevel approach is beneficial for both conceptual and empirical work.

37 Employing the workplace as entry point for studying commuting has another advantage. In contrast to bottom-up approaches which start the analysis with a collection of trips or commuters on the one hand, and top-down approaches that focus on e.g. entire cities or countries on the other, a workplace-oriented approach starts somewhere in between. Choosing a meso-level as main entry point and from there looking downwards to individual commuters and upwards to larger entities (e.g. cities) reduces the tendency to explain the world with simple micro-macro binaries (cf. Jonas, 2006 ; Klein et al., 1999). Indeed, it is preferable to employ a multilevel perspective that takes into account several levels simultaneously (Wegener, 2011), and to start the research from an intermediate position. The case study in the present paper which focuses on one workplace using a 
network perspective thus complements rather than contradicts the hierarchical analysis which makes use of a larger dataset.

Finally, the difference between local and global statistics might be relevant. Up till now, we mainly focused on "global" relationships and regularities. But according to among others Fotheringham et al. (2000) it is at least as interesting to search for exceptions or local "hotspots". Many processes are not constant over space (and time) and instead of considering irregularities as annoying outliers, mapping and analysing these differences might increase our knowledge of the process under study. Multilevel models can be applied to reveal how relationships between variables vary across geographical areas and other examples of "local statistics" are geographically weighted regression (Brunsdon et al., 1998) and Local Indicators of Spatial Association (Anselin, 1995), as applied in e.g. Vanoutrive et al. $(2009,2012 \mathrm{~b})$. Also in transport studies there is a growing interest for irregularities (Marsden and Docherty, 2012) and indeed, while conducting the survey reported in Section 3 we find out that travel behaviour is not that stable and regular.

\section{Concluding discussion}

This paper is built around the question of whether the workplace is a meaningful level of analysis in transport geography. Workplaces seem to be relevant since transport policies increasingly promote interventions at the workplace level (e.g. in the form of employer transport plans) and since workplaces are the sites where the organisation of work coincides with the location of work. To explore the importance of the workplace level we employed Variance Partition Coefficients (VPC). Employing three different samples, we estimated that, depending on the mode, 12 to $65 \%$ of the variance in mode choice can be attributed to the workplace level. Evidently, the application of this exploratory tool is just a start. By adding variables one can explain the variance among workplaces, e.g. Vanoutrive et al. (2012a) explained $41 \%$ of the variance in rail use between worksites by adding variables for accessibility and organisational practices. Furthermore, one can check how the context influences the variable under study, e.g. is travel behaviour directly influenced by corporate culture, indirectly via an intermediate variable like a person's attitude towards environmental concerns, or does corporate culture modify the process between attitude and mode choice (see Blakely and Woodward (2000) for a discussion on ecological effects)?

We subsequently focused on one case, 28 commuters nested in one department, and applied a different methodology (network analysis). This case study challenges the idea that a workplace or department is a single homogeneous entity. However, the case study complements rather than contradicts the hierarchical analysis if seen from a multilevel perspective. From a methodological point of view, using the workplace as entry point to analyse commuting has the advantage that it is a meso-level in between individuals and geographical or administrative areas. As a consequence, a multilevel perspective where the workplace takes an intermediate position has the potential to result in a rich, multifaceted analysis of commuting. This paper contains some inspiration to define a research agenda. One topic that deserves further attention is the analysis of the relations between employees and the dynamics and relevant processes inside workplaces. The impact of household characteristics and the interactions with other household members should be included as well. Inspiration for the workplace-household relation can be found in the feminist literature. The household level was not discussed in this paper but needs 
to be part of more in-depth analyses. The potential impact of workplace-oriented transport strategies might be analysed taking these elements into account. Finally, conceptual models on the effects of mobility management measures on commuting behaviour (e.g. Gärling et al. 2002) can be extended with a focus on higher levels like workplaces.

Acknowledgements

I am grateful to Ann Verhetsel and Toon Zijlstra for their useful comments on an earlier draft of this paper. Inspiration for this paper was also generated during the ADICCT-project. However, all remaining errors are mine.

\section{BIBLIOGRAPHY}

ANSELIN L. (1988), Spatial econometrics : Methods and models, Kluwer Academic Publishers, Dordrecht.

ANSELIN L. (1995), “Local Indicators of Spatial Association-LISA”, Geographical Analysis, 27, pp. 93-115.

AXHAUSEN K.W. (2007), “Activity Spaces, Biographies, Social Networks and their Welfare Gains and Externalities : Some Hypotheses and Empirical Results”, Mobilities, 2, 15-36.

BHAT C.R. (2000), “A multi-level cross-classified model for discrete response variables”, Transportation Research Part B, 34, pp. 567-582.

BLAKELY T.A. and Woodward, A.J. (2000), "Ecological effects in multi-level studies", Journal of Epidemiology and Community Health, 54, pp. 367-374.

BONHAM J. and KOTH B. (2010), “Universities and the cycling culture”, Transportation Research Part D, 15, pp. 94-102.

BRENNER N. (2001), "The limits to scale? Methodological reflections on scalar structuration", Progress in Human Geography, 25, pp. 591-614.

BREWER A.M. (1998), “Work design, flexible work arrangements and travel behaviour : policy implications", Transport Policy, 5, pp. 93-101.

BROWNE W.J., MCCLEERY R.H., SHELDON B.C., and PETTIFOR R.A. (2007), “Using cross-classified multivariate mixed response models with application to life history traits in great tits (Parus major)", Statistical Modelling 7, pp. 217-238.

BROWNE W.J., SUBRAMANIAN S.V., JONES K., and GOLDSTEIN H. (2005), “Variance partitioning in multilevel logistic models that exhibit overdispersion", Journal of the Royal Statistical Society: Series A, 168, pp. 599-613.

BRUNSDON C., FOTHERINGHAM S., and CHARLTON M. (1998), “Geographically Weighted Regression-Modelling Spatial Non-Stationarity”, The Statistician, 47, pp. 431-443.

BUTTS C.T. (2008), “Social Network Analysis with sna”, Journal of Statistical Software, 24. 
CAIRNS S., NEWSON C., and DAVIS A. (2010), "Understanding successful workplace travel initiatives in the UK", Transportation Research Part A, 44, pp. 473-494.

CAIRNS S., SLOMAN L., NEWSON C., ANABLE J., KIRKBRIDE A., and GOODWIN P. (2008), "Smarter choices : Assessing the potential to achieve traffic reduction using 'soft measures"', Transport Reviews, 28, pp. 593-618.

CASEY E.S. (2008), “Questioning 'Theorizing sociospatial relations”, Environment and Planning D, 26 , pp. 402-404.

CHEN C., GONG H., and PAASWELL R. (2008), "Role of the built environment on mode choice decisions : additional evidence on the impact of density", Transportation, 35, pp. 285-299.

CORRADO L. and FINGLETON B. (2011), "Multilevel Modelling with Spatial Effects", Strathclyde Discussion Papers in Economics, 11-05, Department of Economics, University of Strathclyde, Glasgow.

CORRADO L. and FINGLETON B. (2012), "Where is the Economics in Spatial Econometrics ?", Journal of Regional Science, 52, pp. 210-239.

DEHART-DAVIS L. and GUENSLER R. (2005), “Employers as Mediating Institutions for Public Policy : The Case of Commute Options Programs”, Policy Studies Journal, 33, pp. 675-697.

DE WASSEIGE Y., LAFFUT M. RUYTERS C. and SCHLEIPER P. (2000), Bassins d'emploi et régions fonctionelles - méthodologie et définition des bassins d'emploi belges, Ministère de la Région wallonne, Service des Etudes et de la Statistique.

DICKINSON J.E., KINGHAM S., COPSEY, S., and HOUGIE D.J.P. (2003), "Employer travel plans, cycling and gender : will travel plan measures improve the outlook for cycling to work in the UK ?", Transportation Research Part D , 8, pp. 53-67.

DRENNAN M. (2005), "The Human Science of Simulation : A Robust Hermeneutics for Artificial Societies", Journal of Artificial Societies and Social Simulation 8.

DUNCAN C., JONES K., and MOON G. (1998), “Context, composition and heterogeneity : Using multilevel models in health research", Social Science \& Medicine, 46, pp. 97-117.

EISENHARDT K.M., 1989. “Building Theories from Case Study Research”, Academy of Management Review, 14, pp. 532-550.

ESCOBAR A. (2007), “The 'ontological turn' in social theory. A Commentary on 'Human geography without scale', by Sallie Marston, John Paul Jones II and Keith Woodward”, Transactions of the Institute of British Geographers, 32, pp. 106-111.

EUROPEAN COMMISSION 2011. WHITE PAPER, Roadmap to a Single European Transport AreaTowards a competitive and resource efficient transport system, COM(2011) 144 final, Brussels.

FLOWERDEW R., MANLEY D.J., and SABEL C.E. (2008), "Neighbourhood effects on health : Does it matter where you draw the boundaries ?", Social Science \& Medicine, 66, pp. 1241-1255.

FOTHERINGHAM A.S., BRUNSDON C., and CHARLTON M. (2000), Quantitative Geography Perspectives on Spatial Data Analysis, Sage, London.

FRÄNDBERG L. and VILHELMSON B. (2010), "Structuring Sustainable Mobility : A Critical Issue for Geography”, Geography Compass, 4, pp. 106-117.

FRENCH K.M. and JONES K. (2006), "Impact of definition on the study of avoidable mortality : Geographical trends in British deaths 1981-1998 using Charlton and Holland's definitions", Social Science \& Medicine, 62, pp. 1443-1456. 
GÄRLING T., EEK D., LOUKOPOULOS P., FUJII S., JOHANSSON-STENMAN O., KITAMURA R., PENDYALA R., and VILHELMSON B. (2002), "A conceptual analysis of the impact of travel demand management on private car use", Transport Policy, 9, pp. 59-70.

GOLDSTEIN H. (1988), Multilevel Statistical Models, Arnold, London.

GREEN A.E. (2004), "Is Relocation Redundant ? Observations on the Changing Nature and Impacts of Employment-related Geographical Mobility in the UK”, Regional Studies, 38, pp. 629-641.

GROENEWEGEN P.P., LEUFKENS H.G., SPREEUWENBERG P., and WORM W. (1999), "Neighbourhood characteristics and use of benzodiazepines in The Netherlands", Social Science \& Medicine, 48, pp. 1701-1711.

HAYNES R., DARAS K., READING R., and JONES A. (2007), “Modifiable neighbourhood units, zone design and residents' perceptions", Health \& Place, 13, pp. 812-825.

HEINEN E., MAAT K., and van WEE B. (2011), "The role of attitudes toward characteristics of bicycle commuting on the choice to cycle to work over various distances", Transportation Research Part D, 16, pp. 102-109.

HEROD A. (2011), Scale, Routledge, London.

HOEFLE S.W. (2006), "Eliminating scale and killing the goose that laid the golden egg ?", Transactions of the Institute of British Geographers, 31, pp. 238-243.

HOX J.J. (2002), Multilevel Analysis : Techniques and Applications, Erlbaum, Mahwah, NJ.

JESSOP B., BRENNER N., and JONES M. (2008), “Theorizing sociospatial relations”, Environment and Planning D, 26, pp. 389-401.

JOHNSTON R., JONES K., PROPPER C., and BURGESS S. (2007), "Region, Local Context, and Voting at the 1997 General Election in England", American Journal of Political Science, 51, pp. 640-654.

JOHNSTON R.J., GREGORY D., PRATT G., and WATTS M. (2000), The Dictionary of Human Geography, Blackwell, Malden.

JONAS A.E.G. (2006), "Pro scale : further reflections on the 'scale debate' in human geography", Transactions of the Institute of British Geographers, 31, pp. 399-406.

JONES III J.P., WOODWARD K., and MARSTON S.A. (2007), "Situating Flatness", Transactions of the Institute of British Geographers, 32, pp. 264-276.

JONES T., POOLEY C., CHISHOLM A., HORTON D., and SCHELDEMAN G. (2010), Understanding Walking and Cycling: Interim Findings from a Multi-Method Approach to Investigate Household Decision Making in Relation to Short Journeys in Urban Areas, Paper presented at WCTR 2010, Lisbon.

KENDLER K.S. (2005), “Toward a philosophical structure for psychiatry”, American Journal of Psychiatry, 162, pp. 433-440.

KLEIN K.J., TOSI H., and CANNELLA A.A. (1999), "Multilevel theory building : Benefits, barriers, and new developments", Academy of Management Review, 24, pp. 243-248.

KWAN M.P. and WEBER J. (2008), "Scale and accessibility : Implications for the analysis of land use-travel interaction”, Applied Geography, 28, pp. 110-123.

LAM N.S.N. and QUATTROCHI D.A. (1992), “On the Issues of Scale, Resolution, and Fractal Analysis in the Mapping Sciences”, Professional Geographer, 44, pp. 88-98.

LANGFORD I.H., BENTHAM G., and MCDONALD A.-L. (1998), "Multi-level modelling of geographically aggregated health data : a case study on malignant melanoma mortality and UV exposure in the European Community", Statistics in Medicine, 17, pp. 41-57. 
LANGFORD I.H., LEYLAND A.H., JON R., and GOLDSTEIN H. (1999), "Multilevel Modelling of the Geographical Distributions of Diseases”, Applied Statistics, 48, pp. 253-268.

LEENDERS R.T.A.J. (2002), “Modeling social influence through network autocorrelation : constructing the weight matrix", Social Networks, 24, pp. 21-47.

LEITNER H. and MILLER B. (2007), "Scale and the limitations of ontological debate : a commentary on Marston, Jones and Woodward", Transactions of the Institute of British Geographers, 32, pp. 116-125.

LEVINSON D. and WU Y. (2005), “The rational locator reexamined : Are travel times still stable ?", Transportation, 32, pp. 187-202.

LYONS G. and URRY J. (2005), “Travel time use in the information age”, Transportation Research Part A, 39, pp. 257-276.

MACKINNON D. and SHAW J. (2010), "New State Spaces, Agency and Scale : Devolution and the Regionalisation of Transport Governance in Scotland", Antipode, 42, pp. 1226-1252.

MAMADOUH V., KRAMSCH O., and VAN DER VELDE M. (2004), “Articulating Local And Global Scales”, Tijdschrift voor Economische en Sociale Geografie, 95, pp. 455-466.

MANAUGH K., MIRANDA-MORENO L.F., and EL-GENEIDY A.M. (2010), “The effect of neighbourhood characteristics, accessibility, home-work location, and demographics on commuting distances", Transportation, 37, pp. 627-646.

MANLEY D., FLOWERDEW R., and STEEL D. (2006), "Scales, levels and processes : Studying spatial patterns of British census variables”, Computers, Environment and Urban Systems, 30, pp. 143-160.

MARSDEN G. and DOCHERTY I. (2012), "Disruption" : a useful metaphor for transport policy change?, Paper presented at WCTR SIG 10 workshop 2012, Vienna.

MARSTON S.A. (2000), "The social construction of scale”, Progress in Human Geography, 24, pp. 219-242.

MARSTON S.A., JONES J.P., and WOODWARD K. (2005), "Human geography without scale", Transactions of the Institute of British Geographers, 30, pp. 416-432.

MARSTON S.A. and SMITH N. (2001), "States, scales and households : limits to scale thinking ? A response to Brenner", Progress in Human Geography, 25, pp. 615-619.

MARTIN D., NOLAN A., and TRANMER M. 2001. "The application of zone-design methodology in the 2001 UK Census", Environment and Planning A, 33, pp. 1949-1962.

MAYER M. (2008), “To what end do we theorize sociospatial relations ?", Environment and Planning D, 26, pp. 414-419.

McDONALD N.C. (2007), "Travel and the social environment : Evidence from Alameda County, California", Transportation Research Part D, 12, pp. 53-63.

MERLO J., OHLSSON H., LYNCH K.F., CHAIX B., and SUBRAMANIAN S.V. (2009), "Individual and collective bodies : using measures of variance and association in contextual epidemiology", Journal of Epidemiology and Community Health, 63, pp. 1043-1048.

MOHAN J., TWIGG L., BARNARD S., and JONES K. (2005), "Social capital, geography and health : a small-area analysis for England”, Social Science \& Medicine, 60, pp. 1267-1283.

NEWMAN J.P. and BERNARDIN V.L. (2010), "Hierarchical ordering of nests in a joint mode and destination choice model", Transportation, 37, pp. 677-688. 
OPENSHAW S. and TAYLOR P., 1981. "The modifiable area unit problem", in WRIGLEY N. and BENNETT R. (Eds.), Quantitative Geography : A British View, Routledge, London, pp. 60-69.

PEETERS D. and THOMAS I. (2009), "Network Autocorrelation”, Geographical Analysis, 41, pp. 436-443.

POTTER S., RYE T., and SMITH M. (1999), “Tax and green transport plans : a survey of UK experience", Transport Policy, 6, pp. 197-205.

R DEVELOPMENT CORE TEAM (2010), $R$ : A language and environment for statistical computing, $R$ Foundation for Statistical Computing, Vienna.

RICHARDS K. (2009), "Geography and the Physical Sciences Tradition”, in CLIFFORD N.J., HOLLOWAY S.L., RICE S.P., and VALENTINE G. (Eds.), Key Concepts in Geography, $2^{\text {nd }}$ ed. Sage, London, pp. 21-45.

ROBINSON W.S., 1950. "Ecological Correlations and the Behavior of Individuals", American Sociological Review, 15, pp. 351-357.

SCHWANEN T. (2007), "Matter(s) of interest : Artefacts, spacing and timing", Geografiska Annaler Series B, 89B, pp. 9-22.

SCHWANEN T., DIELEMAN F.M., and DIJST M. (2004), “The Impact of Metropolitan Structure on Commute Behavior in the Netherlands : A Multilevel Approach", Growth and Change, 35, pp. 304-333.

SCHWANEN T., and DIJST M. (2002), "Travel-time ratios for visits to the workplace : the relationship between commuting time and work duration", Transportation Research Part A, 36, pp. 573-592.

SHAPIRO M.J. (2008), “Jessop et al's more is better : a political rejoinder", Environment and Planning D, 26, pp. 411-413.

SHELLER M. and URRY J. (2006), “The new mobilities paradigm”, Environment and Planning A, 38, pp. 207-226.

SUBRAMANIAN S.V. (2004), "The relevance of multilevel statistical methods for identifying causal neighborhood effects - Commentary”, Social Science \& Medicine, 58, pp. 1961-1967.

SUBRAMANIAN S.V., DUNCAN C., and JONES K. (2001), "Multilevel perspectives on modeling census data", Environment and Planning A, 33, pp. 399-417.

TAYLOR P.J. (2004), World City Network - A Global Urban Analysis, Routledge, London.

TOBLER W.R. (1970), “A computer movie simulating urban growth in the Detroit region”, Economic Geography, 46, pp. 234-240.

van OMMEREN J., RIETVELD P., and NIJKAMP P. (1999), “Job moving, residential moving, and commuting : A search perspective”, Journal of Urban Economics, 46, pp. 230-253.

van WEE B. (2009), "Self-Selection : A Key to a Better Understanding of Location Choices, Travel Behaviour and Transport Externalities?", Transport Reviews, 29, pp. 279-292.

VANOUTRIVE T., VAN MALDEREN L., JOURQUIN B., THOMAS I., VERHETSEL A., and WITLOX F. (2009), "'Let the business cycle!' A spatial multilevel analysis of cycling to work", Belgeo, 2, pp. 217-232.

VANOUTRIVE T., VAN MALDEREN L., JOURQUIN B., THOMAS I., VERHETSEL A., and WITLOX F. (2010), "Mobility Management Measures by Employers : Overview and Exploratory Analysis for Belgium”, European Journal of Transport and Infrastructure Research, 10, pp. 121-141. 
VANOUTRIVE T., VAN MALDEREN L., JOURQUIN B., THOMAS I., VERHETSEL A., and WITLOX F. (2012a), "Rail Commuting to Workplaces in Belgium : A Multilevel Approach". International Journal of Sustainable Transportation, 6, pp. 67-87.

VANOUTRIVE T., VAN DE VIJVER E., VAN MALDEREN L., JOURQUIN B., THOMAS I., VERHETSEL A., and WITLOX F. (2012b), "What determines carpooling to workplaces in Belgium : location, organisation, or promotion ?”, Journal of Transport Geography, 22, pp. 77-86.

VERHETSEL A., THOMAS I., and BEELEN M. (2010), "Commuting in Belgian metropolitan areas : The power of the Alonso-Muth model”, Journal of Transport and Land Use, 2, pp. 109-131.

VERHETSEL A., and VANELSLANDER T. (2010), "What location policy can bring to sustainable commuting : an empirical study in Brussels and Flanders, Belgium”, Journal of Transport Geography, 18, pp. 691-701.

WEGENER M. (2011), "From Macro to Micro - How Much Micro is too Much ?", Transport Reviews, 31, pp. 161-177.

WHITMEYER J.M. (1994), “Why Actor Models Are Integral to Structural Analysis”, Sociological Theory, 12, pp. 153-165.

\section{APPENDIXES}

\section{The workplace as geographical scale}

In this Annex, we touch upon the question of whether the workplace level might be considered as a geographical scale. The concept of scale has been the subject of a (fierce) debate in human geography with Brenner and Marston as key players. Reference is made to their work but we also briefly discuss the link to quantitative work.

One cannot find the workplace in the standard list of scales (body-urban-regionalnational-global). However, "these are not the only scales" (Herod, 2011, p. 250) and a key argument in a decisive paper in the scale debate argued that a particular scale was largely ignored (the household, the sphere of social reproduction ; see Marston (2000), Brenner (2001) and Marston and Smith (2001)). There are good arguments to consider the workplace as a scale which may not be overlooked in transport geography (Vanoutrive et al., 2012b). However, Brenner (2001) warned that the concept of geographical scale is often used inconsiderately. Scale in its strictest sense relates to a set of scales, the relations between these scales, and the processes that form or weaken these scales and relations (Mamadouh et al., 2004). In other words, the workplace is a scale if the (changing) relations with other scales are analysed. If not, a workplace might be understood as e.g. a place or something else, but not in scalar terms (according to "scalists" like Brenner (2001) who criticized Marston (2000) for an improper use of the concept of scale). The scale debate culminated with the statement of Marston et al. (2005, p. 420) that "we can abandon hierarchical scale in its entirety and put in its place some alternative". They propose a more network-based concept (flat ontology). To close the debate, Jessop et al. (2008) elaborated on suggestions made by among others Brenner (2001) and developed the "territories, places, scales, and networks" (TPSN) framework in order to avoid privileging one dimension of socio-spatial relations (e.g. scale). According to them, these four dimensions (TPSN) "must be viewed as mutually constitutive and 
relationally intertwined dimensions of sociospatial relations" (p.389). This TPSN framework is a useful heuristic for (qualitative) studies, although one can question whether other relevant dimensions exist besides territories, places, scales, and networks (Casey, 2008), or whether the inclusion of an increasing number of dimensions and interactions is the best way to increase the explanatory power of a conceptual model (Mayer, 2008 ; Shapiro, 2008). The debate has continued.

Within the context of this debate, the question "is the workplace a scale" has two dimensions. First, there is the ontological status of the workplace, i.e. are workplaces real, material entities or just mental devices to analyse e.g. commuting behaviour. Among others Herod (2011) puts strong emphasis on the ontological status of scale. Second, do we consider workplaces as scales or as places, territories or something else ? Regarding ontology, it seems reasonable to state that workplaces have ontological status. In general, workplaces are discrete entities, often with access control, located at a particular site. As a consequence, employees share the same accessibility characteristics if they are employed at the same location. Moreover, accessibility is restricted through organisational practices in general and working times in particular. For example, flexible working times enable commuters to attune their work schedules to public transport timetables, or to avoid peak hour congestion (Brewer, 1998 ; Vanoutrive et al., 2012a). Different plants of the same employer might have similar organisational characteristics, but the physical context and the social environment (contacts between colleagues) differ among workplaces. Similarly, workplaces of different employers in the same building do not share the same organisational structure. The workplace is thus the site where location-related factors coincide and interact with organisational factors. This substantiates the claim that workplaces are real things. Note that e.g. teleworking practices might challenge the role of workplaces.

The second issue is whether the workplace can be considered a scale in relational terms. In their transport policies, governments in Belgium and elsewhere lay part of the responsibility on employers. The establishment of mandatory travel plans, subsidy schemes for innovative mobility management schemes at the workplace level, parking standards in land-use planning policies, tax deductibility of bus transport organised by employers, tax exemptions for bicycle allowances and the reimbursement of public transport season tickets are all examples of the "sticks" and "carrots" provided by national, regional and local governments to encourage employers to do some mobility management. At least three levels are involved, the level of decision making (e.g. regional government), the level of intervention (workplace), and the level of (supposed) behavioural change (individual employee). This policy strategy implies differentiation since no two workplaces are the same and accordingly, "travel plans need to be tailored to the specific organisation" (Potter et al., 1999 ; Dickinson et al., 2003, p. 64). As a result, the changing role of workplaces in transport policies might thus be understood in scalar terms.

However, the present paper did not analyse workplaces from a "scalist" perspective, but focused on the workplace as an operational scale, as a "level at which relevant processes operate" (Marston, 2000, p. 220 ; Lam and Quattrochi, 1992). The prime focus is on methodological and quantitative issues, i.e. can we measure how important this level is. Nevertheless, we raise the question whether a link is present between the two divergent literatures (the scale debate vs. statistics). There are many similarities between discussions in the scale debate and in quantitative studies. Relying on prespecified (a 
priori defined) hierarchies, focusing on individual building blocks while ignoring higher levels (reductionism), and being fascinated by network-like structures, are issues present in both the scale literature as well as in statistical studies. As a consequence, one can argue that quantitative studies have a role to play in theoretical debates, either as providers of empirical results, either as quantified metaphors (Drennan, 2005), i.e. why using metaphors of trees, ladders, Russian dolls and roots (Herod, 2011) if models can do the same job, while generating additional information? In their introductory sections, some scale authors refer to quantitative studies that discuss issues like ecological fallacy (e.g. Lam and Quattrochi (1992)) and which are considered as "very useful overviews of how questions of scale are being addressed in physical geography [...] and even statistical analysis" (Marston, 2000, p. 220). But the "first single-author volume ever written on the subject of geographical scale" (Herod, 2011) does not make any reference to the scale effect of MAUP or multilevel modelling (admittedly, the work refers to a wide range of empirical studies, but it illustrates the low level of interaction between the scale literature and quantitative work). The advantage of quantitative approaches is that they make things extremely explicit, i.e. they act as quantified metaphors. To avoid any misunderstanding, we do not expect that a discussion on the role of the workplace in commuting will add much to the debate, but it illustrates our point. In a response to Marston et al. (2005), Hoefle (2006) depicts the hierarchical and alternative politics in his study area using lines, arrows and boxes. Such figures make explicit how he understands scale and since there are clearly "sides" in the debate (Jones III et al., 2007) which tend to speak different languages (or live in different worlds), making things very explicit might be illuminating. An iterative process between theory and empirics is fruitful for both sides (Eisenhardt, 1989). The ultimate example is theoretical physics where huge amounts of effort are spent on measurements (in particle accelerators). In geographical research, Taylor (2004) is a renowned example of a range of empirical analyses which was a response to the combination of "theoretical sophistication and empirical poverty" (p. 33) in world city research. Of course, quantitative techniques oversimplify reality and the examples in this paper do this in an excessive way. Quantitative scholars acknowledge that spatial patterns originate from several distinct processes operating at several different spatial scales, and these scales may vary over space as well. Models can help to detect the relevant scales and can model different spatial scales simultaneously. However, even a complex spatial structure may not entirely grasp the complexity of all spatial processes. (Langford et al., 1998 ; Manley et al., 2006). Nevertheless, measures that focus on verticality like the VPC can be applied to measure the changing relations between levels while network analysis might reveal the role of relations between elements. Moreover, hierarchical and network approaches can be combined (Langford, et al., 1998, 1999 ; Corrado and Fingleton, 2011, 2012). The visualisation of data and models (Figure 1) can be used as a kind of metaphors to ask "do you mean this ?", and can then be applied (in modified form) to measure the object under study. This process can result in the refinement of theoretical models. At least, if we assume commensurability.

\section{ABSTRACTS}

It is often stated that one of the advantages of geography is its ability to include various spatial scales (other than the individual). In transport policy, the workplace is increasingly seen as a level of intervention which, as a consequence, should be researched by geographers. The present 
essay discusses the workplace as level of analysis in transport geography. Exploratory measures indicate that 12 to $65 \%$ of the variance in mode choice can be attributed to this level, with considerable differences between modes. However, these measures ignore the relationships and interactions of and between employees. An alternative, network-based view on workplaces is illustrated by means of a small case study. The empirical examples are the starting point for a discussion of some methodological issues related to analyses at multiple levels.

Il est communément admis que la géographie présente entre autres avantages celui de pouvoir intégrer une variété d'échelles spatiales (outre l'échelle individuelle). Les politiques des transports considèrent de plus en plus le lieu de travail comme un niveau d'intervention qui devrait par conséquent se voir investigué par les géographes. Cet article aborde la question du lieu de travail en tant que niveau d'analyse en géographie des transports. Les mesures exploratoires montrent que 12 à $65 \%$ de la variance des choix modaux peuvent être attribués à ce niveau, avec des écarts considérables entre les modes. Toutefois, ces mesures ne prennent pas en compte les relations et interactions des (ou entre) travailleurs. Un point de vue alternatif axé sur les réseaux est illustré ici par une étude de cas succincte. Les exemples empiriques sont le point de départ d'une discussion centrée sur différents problèmes méthodologiques relatifs aux analyses multi-niveaux.

INDEX

Mots-clés: géographie des transports, lieu de travail, partitionnement des variances, échelle Keywords: transport geography, workplace, variance partitioning, scale

\section{AUTHOR}

\section{THOMAS VANOUTRIVE}

Department of Transport and Regional Economics, University of Antwerp,

Thomas.Vanoutrive@ua.ac.be 